\title{
Congenital midline cervical cleft: An easily misdiagnosed disease
}

\author{
Byungkwon Kang, \\ Byungjun Kim \\ Department of Plastic and \\ Reconstructive Surgery, Seoul National \\ University Hospital, Seoul, Korea
}

\begin{abstract}
Congenital midline cervical cleft is a rare congenital disease. The disease is often misdiagnosed as a branchial cleft deformity, thyroglossal duct cyst, or other skin diseases. It has the following characteristics: skin defect at the midline of the anterior neck, a skin tag at the upper end of the lesion, and a blind sinus tract at the caudal aspect with or without mucoid discharge. Treatment is usually for aesthetic purposes; therefore, early surgical en bloc resection with Z-plasty or W-plasty is recommended to reduce recurrence and scar formation.
\end{abstract}

Keywords: Cervicoplasty / Humans / Skin abnormalities / Thyroglossal cyst

\section{INTRODUCTION}

Congenital midline cervical cleft (CMCC) is a rare congenital disease that is often detected in childhood. The disease is often misdiagnosed as a branchial cleft deformity, thyroglossal duct cyst (TGDC), or other skin diseases. In this report, we describe a case of CMCC with a brief review of this uncommon disease to provide information and prevent its misdiagnosis secondary to its low incidence.

\section{CASE REPORT}

A 4-year-old boy visited our outpatient clinic of the department of plastic and reconstructive surgery with an anterior neck lesion apparent from birth (Fig. 1). The patient initially visited an outpatient clinic of the department of otorhinolaryngology and was diagnosed with TGDC. He was then referred to our clinic due to aesthetic concerns about scarring after surgery. The patient had no notable medical or familial history of similar lesions.

\section{Correspondence: Byungjun Kim}

Department of Plastic and Reconstructive Surgery, Seoul National University

Hospital, 101 Daehak-ro, Jongno-gu, Seoul 03080, Korea

E-mail: bjkim79@gmail.com

Received July 27, 2020 / Revised October 10, 2020 / Accepted December 2, 2020
On physical examination, the lesion showed three characteristic features: (1) a 3-cm long and 1-cm wide longitudinal skin defect lesion at the midline of the anterior neck, (2) a skin taglike structure at the cephalic end of the lesion, and (3) a pinhole defect at the caudal end of the lesion. The patient underwent sonography, which revealed a heterogeneous lesion of the dermis and subcutaneous layer with a non-vascular, hypoechoic, blinded sinus tract (Fig. 2). Without further evaluation, the patient was diagnosed with CMCC.

An en bloc excision, including subcutaneous tissue, was performed under general anesthesia (Fig. 3). Using a lacrimal probe, the blind end of the sinus pocket was identified. The resected specimen was sent to the pathology department for histopathologic examination. Sufficient undermining of subcutaneous tissue and Z-plasty were performed to prevent scar widening. The patient was discharged on the day of surgery without any postoperative complications.

Histopathological examination showed typical pathologic findings of CMCC (Fig. 4). Two months post-surgery, the patient showed no evidence of recurrence or major complications (Fig. 5). Hypertrophic scar changes were observed. However, the patient felt more comfortable moving his neck after the release of a contracture caused by a fibrous band. 


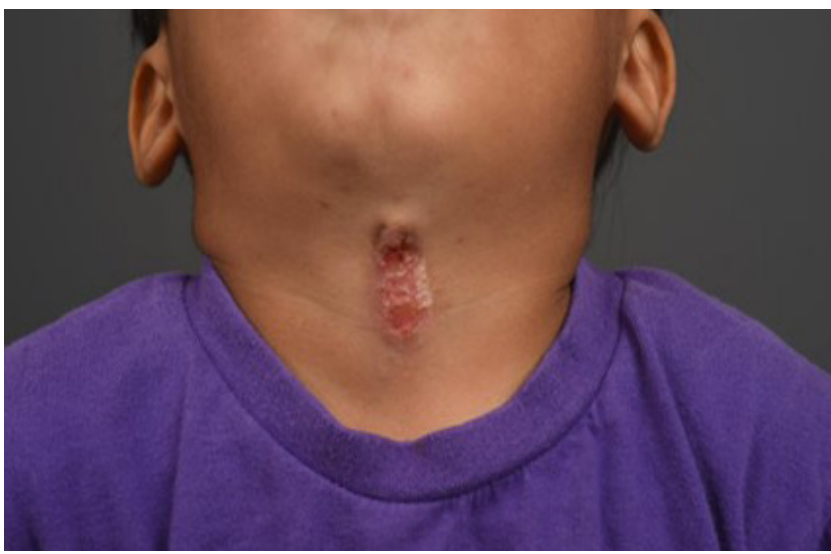

Fig. 1. Preoperative photograph of a patient with congenital midline cervical cleft (CMCC). It shows pathognomonic features of CMCC: skin tag-like structure at the cephalic end, scar-like skin defect in the middle, and sinus opening at the caudal end.

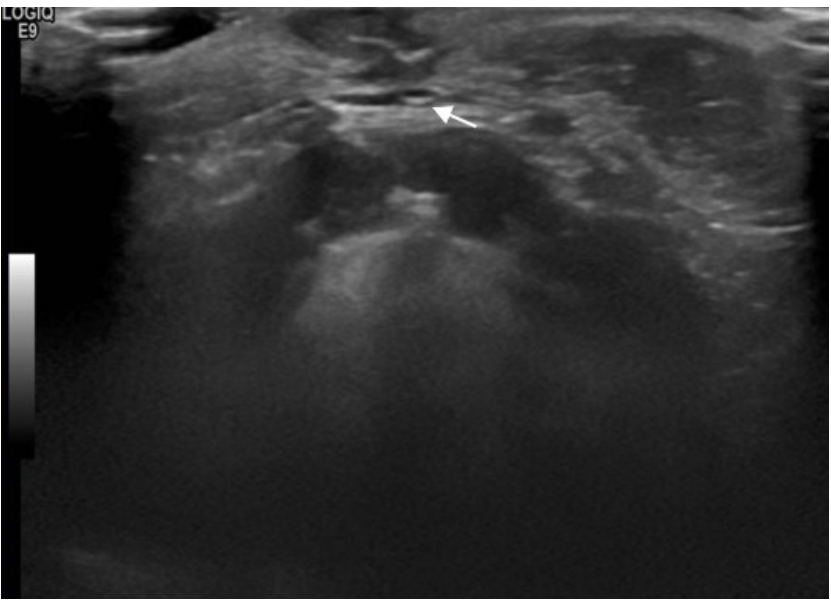

Fig. 2. Ultrasonography of the cervical region showing a non-vascular, hypoechoic tract (white arrow).
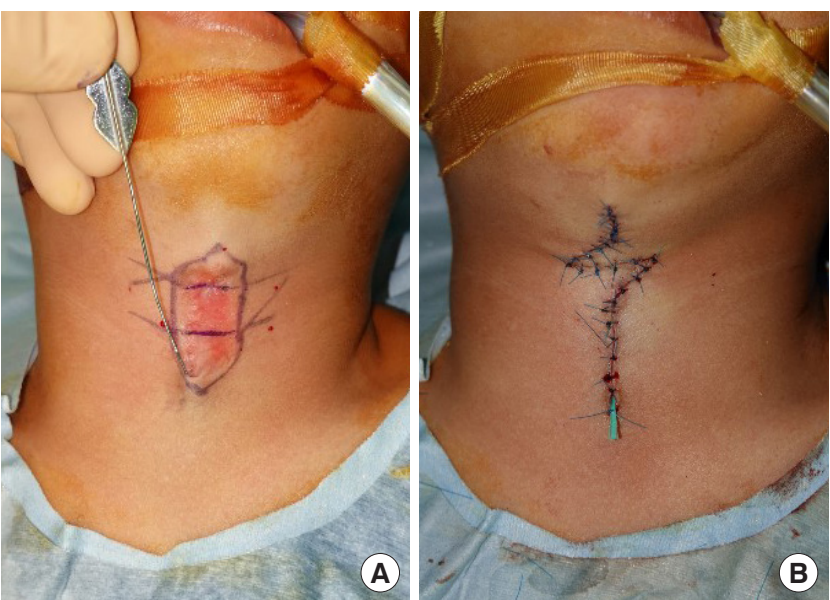

Fig. 3. Intraoperative photographs. (A) En bloc excision of the lesion was performed to prevent recurrence. (B) Substantial dissection of the adjacent subcutaneous layer and Z-plasty were performed to reduce scar tension.
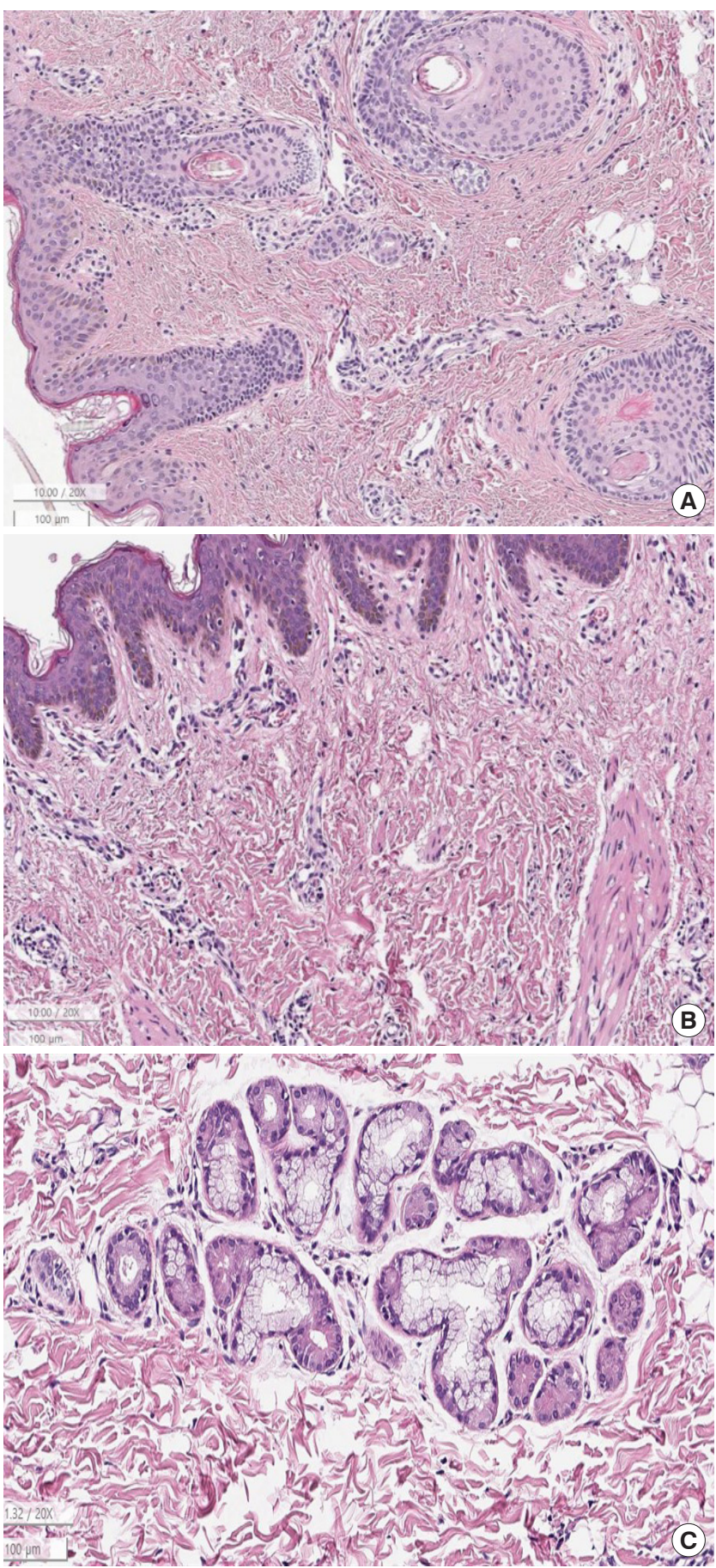

Fig. 4. Histopathologic figures of congenital midline cervical cleft. (A) At the cephalic end, parakeratotic squamous epithelium and adnexal structures, such as sweat gland ducts and hair follicles with bundles of striated muscle are observed $(\mathrm{H} \& \mathrm{E}, \times 10)$. (B) In the center of the lesion, parakeratotic squamous epithelium without adnexal structure is visible $(\mathrm{H} \& \mathrm{E}, \times 10)$. (C) The caudal end has gland ducts surrounded by seromucinous glands $(\mathrm{H} \& \mathrm{E}, \times 10)$.

\section{DISCUSSION}

CMCC is a rare congenital disease that is considered a variant of 
the cleft category number 30 of the Tessier classification system of craniofacial defects [1]. It was first described in English literature by Bailey in 1924 [2]. A detailed description of its unique manifestation was presented by Ombredanne in 1949 [3]. By 2015, there were reports of about 200 cases in English literature, including the first case report in a Korean journal published in English in 2014 [4,5]. Moreover, there is insufficient data on the clinical, histological, and radiologic characteristics of CMCC compared with TGDC, which is the most common differential diagnosis of CMCC.

This disease has the following characteristics: (1) possible atrophy of the skin at any level between the chin and sternal notch; (2) a nipple-like projection (skin tag) at the upper end of the fissure; (3) a blind sinus tract at the caudal aspect, which may discharge mucoid material; and (4) a subcutaneous cordlike fibrous thickening that may cause webbing [6].

The histopathologic features of CMCC are also divided into three portions. The cephalic skin tag-like structure consists of parakeratotic squamous epithelium and adnexal structures,

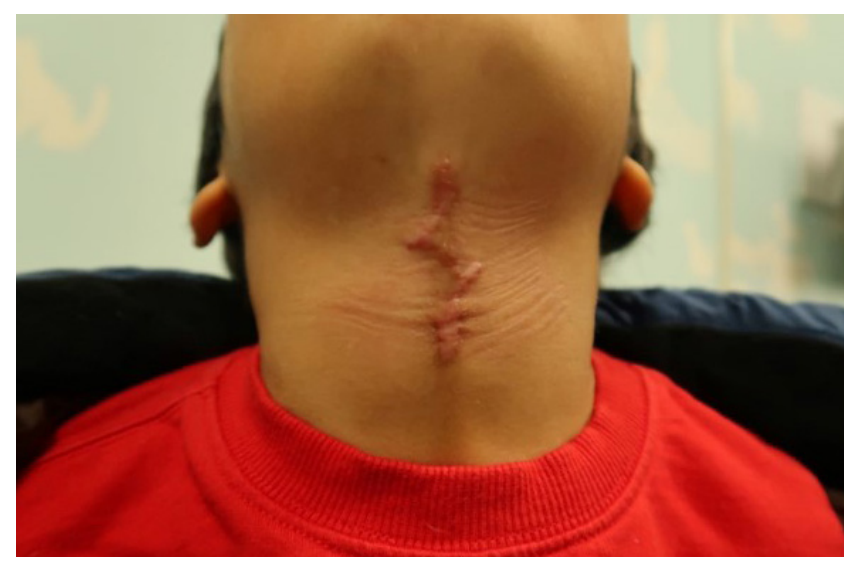

Fig. 5. Postoperative photograph at 2-month follow-up visit. such as sweat gland ducts and hair follicles. In the middle portion, it consists of parakeratotic stratified squamous epithelium without adnexal structures underneath. At the caudal end are seromucinous glands in the dermis layer as well as the characteristic upper respiratory type pseudostratified ciliated epithelium at the sinus ending [7].

CMCC is often initially misinterpreted by physicians as a branchial cleft deformity, TGDC, or other congenital malformations [8,9]. Gargan et al. [10] reported 12 misdiagnosed midline cervical cleft cases from 612 thyroglossal diseases and branchial cleft sinus diseases in 30 years. Gross and Connerley [11] reported two misdiagnosed cases out of 198 cases (2\% incidence) of congenital neck malformation. Therefore, it is important to distinguish CMCC from other congenital neck malformations, especially TGDC, which is the most common type of congenital neck disease. Both of these diseases occur at the midline of the anterior neck; however, TGDC is a cystic mass occurring in the deeper layer. Therefore, imaging modalities, such as computed tomography or ultrasound would be necessary to detect TGDC. Furthermore, TGDC would require a more thorough evaluation because of the possibility of ectopic thyroid and malignant changes. The clinical, histological, and radiologic characteristics of CMCC and TGDC are summarized in Table 1.

Several studies have suggested that there may be a predominance of the disease in the Caucasian population, mainly in women, but the results were not statistically significant $[12,13]$. Jakobsen et al. [14] performed a genetic analysis in three cases of midline cervical cleft in 2012. In this study, two mutations were found: deletion of the pregnancy-associated plasma protein A and mutation in the SIX5 gene. The study concluded that these mutations do not directly cause the disease, but could be contributing factors. Agag et al. [15] found that it was associ-

Table 1. Clinical, histological, and radiological characteristics of congenital midline cervical cleft and thyroglossal duct cyst

\begin{tabular}{|c|c|c|}
\hline & Congenital midline cervical cleft & Thyroglossal duct cyst \\
\hline Clinical features & $\begin{array}{l}\text { - Midline skin defect } \\
\text { - Nipple-like projection (skin tag) at the cephalic end } \\
\text { - Sinus tract at the caudal end }\end{array}$ & -A painless cystic midline neck mass with/without infection \\
\hline Histologic findings & $\begin{array}{l}\text { - Cephalic end: Stratified squamous epithelium with parakeratosis and } \\
\text { striated muscle in the dermis } \\
\text { - Middle: Stratified squamous epithelium with parakeratosis and striated } \\
\text { muscle, but no adnexa } \\
\text { - Caudal end: Pseudostratified ciliated epithelium at the sinus ending and } \\
\text { seromucinous gland in the dermis }\end{array}$ & $\begin{array}{l}\text { - Nonkeratinizing squamous epithelium in the upper neck } \\
\text { - Stratified cuboidal epithelium in the middle } \\
\text { - Pseudostratified ciliated columnar epithelium in the lower neck } \\
\text { - Absence of epithelium of the cystic lesion and often consist of thyroid } \\
\text { follicles in the cyst or duct wall }\end{array}$ \\
\hline Radiologic findings & $\begin{array}{l}\text { - On ultrasound, a non-vascular blind ending sinus tract from the skin } \\
\text { surface } \\
\text { - On computed tomography, skin thinning and a linear tract without } \\
\text { invasion of normal structures of the neck or thyroid }\end{array}$ & $\begin{array}{l}\text { - On ultrasound, fluctuant cystic structures with thin walls and no } \\
\text { vascularity } \\
\text { • On computed tomography, thin-walled, smooth, well-defined } \\
\text { homogeneously fluid-density lesions }\end{array}$ \\
\hline Common misdiagnosis & - Thyroglossal duct cyst & -Ectopic thyroid \\
\hline
\end{tabular}


ated with 13/14 de novo Robertsonian translocations.

Treatment is usually for aesthetic purposes; therefore, early surgical en bloc resection with Z-plasty or W-plasty is recommended to reduce recurrence and scar formation [16].

\section{NOTES}

\section{Conflict of interest}

No potential conflict of interest relevant to this article was reported.

\section{Ethical approval}

The study was approved by the Institutional Review Board of Seoul National University Hospital (IRB No. 2004-124-1117). The study was performed in accordance with the principles of the Declaration of Helsinki. The informed consent was exempted.

\section{Patient consent}

The patient's guardian provided written informed consent for the publication and the use of patient images.

\section{ORCID}

Byungkwon Kang https://orcid.org/0000-0002-7704-0786

Byungjun Kim https://orcid.org/0000-0002-6891-3768

\section{REFERENCES}

1. Tessier P. Anatomical classification facial, cranio-facial and latero-facial clefts. J Maxillofac Surg 1976;4:69-92.

2. Bailey H. Thyroglossal cysts and fistulase. Br J Surg 1925;12: 579-89.

3. Ombredanne L. Precis Clinique et Operatoire de Chirurgie Infantile. 5th ed. Paris: Masson; 1949.
4. Puscas L. Midline cervical cleft: review of an uncommon entity. Int J Pediatr 2015;2015:209418.

5. Eom TK, Sun H, Yoon HK. Congenital midline cervical cleft. Arch Plast Surg 2014;41:429-31.

6. Maddalozzo J, Frankel A, Holinger LD. Midline cervical cleft. Pediatrics 1993;92:286-7.

7. Sinopidis X, Kourea HP, Panagidis A, Alexopoulos V, Tzifas S, Dimitriou G, et al. Congenital midline cervical cleft: diagnosis, pathologic findings, and early stage treatment. Case Rep Pediatr 2012;2012:951040.

8. Chang LS. Common pitfall of plastic surgeon for diagnosing cutaneous odontogenic sinus. Arch Craniofac Surg 2018;19: 291-5.

9. Kim H, Chung JH, Sung HM, Kim S. Rhabdomyomatous mesenchymal hamartoma presenting as a midline mass on a chin. Arch Craniofac Surg 2017;18:292-5.

10. Gargan TJ, McKinnon M, Mulliken JB. Midline cervical cleft. Plast Reconstr Surg 1985;76:225-9.

11. Gross RE, Connerley ML. Thyroglossal cysts and sinuses: a study and report of 198 cases. N Engl J Med 1940;223:616-24.

12. Van Duyn J. Congenital midline cervical cord with report of a case and a note on the etiology of congenital torticollis. Plast Reconstr Surg 1963;31:576-86.

13. Hirokawa S, Uotani H, Okami H, Tsukada K, Futatani T, Hashimoto I. A case of congenital midline cervical cleft with congenital heart disease. J Pediatr Surg 2003;38:1099-101.

14. Jakobsen LP, Pfeiffer P, Andersen M, Eiberg H, Hansen L, Mang Y, et al. Genetic studies in congenital anterior midline cervical cleft. Am J Med Genet A 2012;158A:2021-6.

15. Agag R, Sacks J, Silver L. Congenital midline cervical cleft. Cleft Palate Craniofac J 2007;44:98-101.

16. D’Souza JN, Valika T, Maddalozzo J. Surgical management of midline cervical cleft. Int J Pediatr Otorhinolaryngol 2019;127: 109657. 